\title{
Longitudinal changes in dietary intake in Scottish women around the menopause: changes in dietary pattern result in minor changes in nutrient intake
}

\author{
Helen M Macdonald ${ }^{1, *} \dagger$, Susan A New ${ }^{2}$ and David M Reid ${ }^{1}$ \\ 'Department of Medicine and Therapeutics, University of Aberdeen, Medical School Buildings, Foresterhill, \\ Aberdeen AB25 2ZD, UK: ${ }^{2}$ Centre for Nutrition and Food Safety, School of Biomedical and Molecular Sciences, \\ University of Surrey, Guildford, Surrey, GU2 7XH, UK
}

Submitted 5 July 2004: Accepted 22 November 2004

\begin{abstract}
Objective: To examine dietary change that has occurred over 5 to 6 years. Subjects: A cohort of Scottish women $(n=898)$ with a mean age of 47.5 years (range $45-54$ years) at baseline.

Design: Dietary intake was assessed by validated food-frequency questionnaire (FFQ) and analysed using the UK Composition of Foods database.

Results: Since the first dietary assessment, mean daily energy intake had decreased from $8.2 \pm 2.3$ to $7.9 \pm 2.2 \mathrm{MJ}$. The degree of low energy reporting (defined as ratio of energy intake to basal metabolic rate $<1.1$ ) had increased from $18.7 \%$ at baseline to $25.6 \%$ at follow-up. Low energy reporters were significantly heavier than 'normal' energy reporters (mean weight at follow-up, $68.9 \pm 12.6$ vs. $66.8 \pm 11.3 \mathrm{~kg}$ ) and could be deliberately restricting intake rather than underreporting. Overall there were decreases in intakes of red meat, processed meat and cheese, but increases in poultry and non-oily fish consumption. Consumption of bread, biscuits and cakes had gone down and there was an increase in cereal and rice/pasta consumption. Intake of potatoes had decreased whereas fruit intake had increased. There were small but statistically significant differences in intakes for most nutrients ( $<8 \%$ change). Nutrient intakes at both visits were similar across menopausal status and usage groups of hormone replacement therapy. Modifications to the computer version of the McCance and Widdowson nutrient database, which differed from the published version, were noted. These changes altered the original baseline values for our study. Conclusions: The menopause per se is not a period of marked change in nutrient intake. Caution is advised when using computer databases of food compositions for longitudinal studies.
\end{abstract}

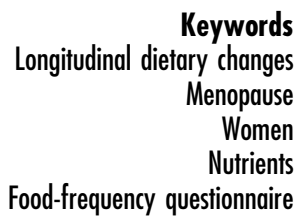

There is little information available on long-term $(>5$ year) changes in dietary patterns or nutrient intake in specific populations. In particular, we do not know whether nutrient intake remains relatively fixed once women reach adulthood or whether the period around the menopausal transition is one of marked dietary change.

Changes in dietary patterns have been observed in a random sample of British adults between 1984/85 and 1991/92 that appeared to be associated with alterations in lifestyle or a change in health circumstances ${ }^{1}$. The National Food Survey $(\mathrm{NFS})^{2}$ has reported several long-term changes in key food groups over the last 25 years, such as decreased consumption of milk but an increase in milk products; increase in fruit consumption but a decreased

†Address for correspondence: Osteoporosis Research Unit, Victoria Pavilion, Woolmanhill Hospital, Aberdeen AB25 1LD, UK. intake of green vegetables. The National Diet and Nutritional Survey (NDNS) of 2000/01 for 18-64-yearolds has recently reported key changes in a number of food groups (meat, milk, vegetables, fruit, fish and beverages) and their associated nutrients since the 1986/ 87 survey $^{3}$. However, these large studies are a series of cross-sectional investigations across the population of the UK. There is a paucity of data that are truly longitudinal in that the same individuals and dietary assessment tools are used throughout the study. Many epidemiological studies use dietary data for ranking individuals in relation to disease outcome. Whether changes in dietary pattern and nutrient intake over a 5-year period influence ranking of individuals is not known.

The aims of the present study were:

1. To investigate whether there were any differences in food groups or nutrient intake over a 6 -year period in a 
cohort of Scottish women who were late premenopausal at their first assessment in 1993; and

2. To find whether these changes led to a change in ranking of individuals for specific nutrients.

\section{Methods}

\section{Subjects}

A group of 1062 healthy, mainly premenopausal women aged between 45 and 54 years who took part in the Aberdeen Prospective Osteoporosis Screening Study (APOSS) in 1990-1993 and who went on to complete dietary questionnaires in $1993^{4}$ form the basis of our study group. APOSS is a population-based screening programme for osteoporotic fracture risk involving over 5000 women, drawn at random using Community Health Index records from a 25-mile radius around Aberdeen ${ }^{5,6}$. A total of 907 (85.2\%) women returned for a repeat bone scan in 1997-1999 and 898 (99\%) women completed a second food-frequency questionnaire (FFQ) identical to that completed in $1993^{7}$. The mean time difference between completing the two FFQs was $5.07 \pm 0.27$ years (range 4.75-6.04 years). Most of the women (93\%) were confirmed as premenopausal but for the remaining $7 \%$ there were some inconsistencies between replies at baseline and follow-up. None had taken hormone replacement therapy (HRT) at the time of their first scan. At the second visit women were assigned to different categories depending on their menopausal status/HRT usage. Such data were unavailable for four women. Women were classified as premenopausal if they had regular menses $(n=51)$ and perimenopausal if they were suffering from irregular menses $(n=96)$. Women who had ceased menstruating for 6 months and had never taken HRT were defined as postmenopausal (non-HRT) users $(n=348)$; women who had taken HRT were classified either as past HRT users $(n=112)$ or present HRT users $(n=286)$.

The study was approved by the Grampian Joint Ethical Committee.

\section{Usual dietary intake}

Usual dietary intake (over the previous 12 months) was assessed by the same FFQ that had been used in a study of diet and bone health ${ }^{4,7}$. A similar questionnaire was used for the Scottish Heart Health Study ${ }^{8,9}$, which was based on the Caerphilly FFQ ${ }^{10}$. The FFQ was modified slightly to include foods commonly consumed in north-east Scotland and contains 98 food items. It has been validated against 7-day weighed records and biochemical markers of antioxidant status, and its short-term (6-week) and longterm (1-year) reproducibility were assessed ${ }^{11,12}$. For the longitudinal investigation, women were sent the FFQ by post. At their visit to our unit most women brought the completed FFQ with them and this was checked for any missed questions that could be rectified while the subject was still present. The FFQs were coded and analysed using the Rowett Research Institute Program (RONA), which uses data from McCance and Widdowson's food composition tables ${ }^{13}$ and which are provided in database form by the Food Standards Agency (formerly the Ministry of Agriculture, Fisheries and Foods, MAFF) and the Royal Society of Chemistry. In terms of both baseline and followup data there was no difference in nutrient intake between the summer and winter groups. Therefore the combined data for summer and winter were used throughout. In addition to comparing crude nutrient intakes, changes in nutrient density standardised to an 8.0-MJ diet (nutrient intake divided by energy intake multiplied by 8) were also examined.

\section{Pbysical activity level}

An estimation of physical activity level (PAL) was obtained by the same questionnaire as used for the Scottish Heart Health Study ${ }^{14}$. PAL was calculated from the numbers of hours in a 24-h period doing heavy, moderate or light activities and how many hours were spent sleeping or resting in bed. The questions were asked separately for working and non-working days.

\section{Statistical analysis}

The statistical package SPSS version 11.0 (SPSS Inc., Chicago, IL, USA, 2000) was used for statistical analyses. Difference in nutrient intake was examined by paired $t$-tests. Where nutrient variables were skewed they were transformed using the natural logarithm. Comparisons were made for crude nutrient intake and nutrient density (nutrient divided by energy in MJ, and multiplied by 8 , which is the Estimated Average Requirement of energy for women aged 50 to 59 years). The latter measurement gives a measure of the quality of the diet. We also examined the percentage of women who had moved more than one quartile for each nutrient, as the different ranking of individuals could influence the results obtained when using the FFQ in epidemiological studies. A measure of agreement between the ranking on both occasions was given by the weighted kappa statistic (Kw). Values of $\mathrm{Kw}$ between 0.61 and 0.80 indicate good agreement, between 0.41 and 0.60 moderate agreement, 0.21 and 0.40 fair agreement, and $<0.21$ poor agreement ${ }^{15}$.

\section{Results}

\section{Responders and non-responders}

Of the women who returned to our unit, 477 (52.6\%) attended between April and September ('summer group') and 430 (47.4\%) between October and March ('winter group'). Thirty-one women were recorded by primary care to have moved away from the area and 35 additional women were not at the address given by primary care, making a total of 66 women (6.2\%) who were 
unobtainable. A further 91 women (8.6\%) did not want to take part this time. Comparing the women who did not complete the FFQ at the second visit and those who did (Table 1), the former were slightly heavier and drank more alcohol but this was not statistically significant.

\section{Changes in subject characteristics}

Anthropometric characteristics at the baseline and followup visits (Table 2) show that the mean weight and body mass index (BMI) of the women had increased. Mean height had diminished by a small decrement. Dietary energy intake, PAL and ratio of energy intake to basal metabolic rate (EI/BMR) had all decreased since the first visit. The menopausal/HRT status of the women had changed.

\section{Low and high energy reporters}

Using EI/BMR $<1.1$ as our definition for low energy reporting, $18.7 \%$ of women at baseline and $25.6 \%$ at follow-up were below this value. Increasing the EI/BMR cut-off to 1.2 defined $29.5 \%$ of the women as low energy reporters at baseline and $38.5 \%$ at follow-up. At the other extreme, $2.2 \%$ of the women had EI/BMR $>2.5$ at baseline compared with $1.2 \%$ at follow-up. Women who were low energy reporters $(\mathrm{EI} / \mathrm{BMR}<1.1)$ at the follow-up visit were significantly heavier than 'normal' energy reporters at both baseline $(65.6 \pm 12.1$ vs. $63.5 \pm 10.5 \mathrm{~kg})$ and follow-up visits $(68.9 \pm 12.6 \mathrm{~kg}$ vs. $66.8 \pm 11.3 \mathrm{~kg})$. The low energy reporters were no different in terms of socioeconomic status ( $\chi^{2} P=0.377$, data not shown). Twice as

Table 1 Comparison of responders and non-responders at the second visit. Values are expressed as mean (standard deviation)

\begin{tabular}{|c|c|c|c|}
\hline & $\begin{array}{l}\text { Responders } \\
\quad(n=898)\end{array}$ & $\begin{array}{c}\text { Non-responders } \\
\quad(n=164)\end{array}$ & $P$-value* \\
\hline Height (cm) & $161.4(5.7)$ & $161.8(5.5)$ & 0.43 \\
\hline Weight (kg) & $64.1(11.0)$ & $65.6(12.1)$ & 0.15 \\
\hline $\begin{array}{l}\text { Body mass index } \\
\left(\mathrm{kg} \mathrm{m}^{-2}\right)\end{array}$ & $24.6(4.0)$ & $25.0(4.2)$ & 0.24 \\
\hline Energy intake (MJ) & $8.2(2.3)$ & $8.0(2.4)$ & 0.31 \\
\hline $\begin{array}{l}\text { Physical activity } \\
\text { level (PAL) }\end{array}$ & $1.88(0.31)$ & $1.89(0.33)$ & 0.98 \\
\hline Alcohol (g day $\left.{ }^{-1}\right)$ & $6.7(7.9)$ & $8.3(8.3)$ & 0.05 \\
\hline
\end{tabular}

* Paired $t$-test comparison with responders after natural log transformation.

Table 2 Subject characteristics at baseline and follow-up. Values are expressed as mean (standard deviation)

\begin{tabular}{lccr}
\hline Characteristic & Baseline & Follow-up & $P$-value \\
\hline Weight $(\mathrm{kg})$ & $64.1(11.0)$ & $67.4(11.7)$ & $<0.001$ \\
Height $(\mathrm{cm})$ & $161.4(5.7)$ & $160.6(5.8)$ & $<0.001$ \\
Body mass index $\left(\mathrm{kg} \mathrm{m}^{-2}\right)$ & $24.6(4.0)$ & $26.1(4.4)$ & $<0.001$ \\
Energy (MJ) & $8.2(2.3)$ & $7.9(2.2)$ & $<0.001$ \\
Physical activity level (PAL) & $1.88(0.31)$ & $1.86(0.33)$ & 0.025 \\
El/BMR & $1.44(0.40)$ & $1.36(0.39)$ & $<0.001$ \\
\end{tabular}

El/BMR - ratio of energy intake to basal metabolic rate. many of the low energy reporters claimed to be on a weight-reducing diet compared with the rest of the study population $\left(16.2 \%\right.$ vs. $\left.8.1 \%, \chi^{2} P<0.001\right)$. There was no difference in the numbers of smokers (18.0\% vs. $17.0 \%$ in the rest of the group, $\chi^{2} P=0.728$ ).

\section{Discrepancies in food composition tables}

Initially, we found surprisingly large differences between baseline and follow-up intakes for vitamin D. Although the use of specific food codes should have ensured that the same database values were being used to analyse the FFQs as had been used at the baseline visit, we found by reanalysing some of the baseline FFQs that the same nutrient values were not being generated. All data from the baseline FFQs were subsequently reanalysed using the currently available database (which did not include the new data on vitamin $\mathrm{D}$ in meat). A selection of the changes observed for specific nutrients is shown in Table 3, demonstrating significant differences in intakes of vitamin C, potassium, fat and in particular vitamin D.

\section{Supplement use}

A number of women reported taking vitamin or mineral supplements including cod-liver oil, evening primrose oil, vitamin $\mathrm{C}$ and multivitamin preparations. The number of women taking supplements increased from 227 (25\%) at baseline to $330(37 \%)$ at the follow-up visit. Just over half the women (55\%) were not taking any supplements either at baseline or follow-up; 9\% of women were taking a supplement at baseline but had stopped; and 16\% of women reported taking a supplement at both visits. The remaining 20\% women had started taking supplements since the first visit.

The majority took cod-liver oil (the latter providing vitamin D and retinol) or evening primrose oil (containing vitamin E). There was a wide variation in the quantities taken for all supplements (Table 4).

Table 3 Comparison* of baseline data (original and reanalysed) with follow-up data (5-year). Values are expressed as mean (standard deviation)

\begin{tabular}{lccc}
\hline & \multicolumn{2}{c}{ Baseline } & \\
\cline { 2 - 3 } & Original & Reanalysed & Follow-up \\
\hline Magnesium $(\mathrm{mg})$ & $314(83)$ & $314(83)$ & $307(81) \ddagger$ \\
Calcium $(\mathrm{mg})$ & $1052(327)$ & $1051(327)$ & $1033(326)$ \\
Phosphorus $(\mathrm{mg})$ & $1475(394)$ & $1479(394)$ & $1452(388) \dagger$ \\
Potassium $(\mathrm{mg})$ & $3346(787)$ & $3355(789) \dagger$ & $3328(786)$ \\
Vitamin E (mg) & $6.52(2.16)$ & $6.53(2.16)$ & $6.59(2.17)$ \\
Vitamin D ( $\mu \mathrm{g})$ & $3.20(2.07)$ & $3.88(2.48) \ddagger$ & $4.06(2.43) \dagger$ \\
Vitamin C (mg) & $117(66)$ & $120(65) \ddagger$ & $122(59) \dagger$ \\
Energy (MJ) & $8.16(2.28)$ & $8.17(2.28)$ & $7.86(2.21) \ddagger$ \\
Fat (g) & $73.7(28.4)$ & $74.0(28.5) \ddagger$ & $68.9(26.7) \ddagger$ \\
Carbohydrate $(\mathrm{g})$ & $245(71)$ & $245(71)$ & $240(70) \dagger$ \\
Protein $(\mathrm{g})$ & $81.0(22.2)$ & $81.1(22.2)$ & $79.2(21.3) \dagger$ \\
\hline
\end{tabular}

* Paired $t$-test comparison after natural log transformation. $+P<0.05$. $\ddagger P<0.01$. 
Table 4 Number of women taking dietary supplements at each visit and amount consumed

\begin{tabular}{|c|c|c|c|c|c|c|c|}
\hline \multirow[b]{3}{*}{ Supplement* } & \multicolumn{3}{|c|}{ Baseline visit } & \multicolumn{3}{|c|}{ Follow-up visit } & \multirow{3}{*}{$\frac{\text { Both visits }}{n(\%)}$} \\
\hline & \multirow[b]{2}{*}{$n(\%)$} & \multicolumn{2}{|c|}{ Amount of supplement } & \multirow[b]{2}{*}{$n(\%)$} & \multicolumn{2}{|c|}{ Amount of supplement } & \\
\hline & & Mean (SD) & Min-max & & Mean (SD) & Min-max & \\
\hline Calcium $\left(\mathrm{mg} \mathrm{day}^{-1}\right)$ & $43(5)$ & $325(277)$ & $20-900$ & $67(8)$ & $383(259)$ & $20-1000$ & $18(2)$ \\
\hline Vitamin C $\left(\mathrm{mg} \mathrm{day}^{-1}\right)$ & $80(9)$ & $141(293)$ & $10-2000$ & $133(15)$ & $162(224)$ & $25-1060$ & $39(4)$ \\
\hline Vitamin $D\left(\mu\right.$ day $\left.^{-1}\right)$ & 120 (13) & $4.4(2.2)$ & $2.5-15$ & $211(24)$ & $6.0(2.9)$ & $1.25-22.5$ & $61(7)$ \\
\hline Vitamin $\mathrm{E}\left(\mathrm{mg} \mathrm{day}^{-1}\right)$ & $129(14)$ & $12.2(23.1)$ & $0.33-167$ & $193(22)$ & 30.9 (63.3) & $0.33-310$ & $57(6)$ \\
\hline Retinol $\left(\mu\right.$ gay $\left.^{-1}\right)$ & $104(11)$ & $886(323)$ & $400-2400$ & $206(23)$ & $944(346)$ & $800-2400$ & $53(6)$ \\
\hline
\end{tabular}

SD - standard deviation.

${ }^{*}$ Reference nutrient intakes for calcium $700 \mathrm{mg}$, vitamin C $40 \mathrm{mg}$, vitamin D $0 \mu \mathrm{g}$ or $10 \mu \mathrm{g}$ for at-risk groups, retinol $600 \mu \mathrm{g}$.

\section{Changes in consumption of food groups}

Overall there was a decrease in the intakes of red meat, processed meat, cheese, bread, biscuits, cakes, potatoes and coffee, and an increase in poultry, non-oily fish, cereal, rice/pasta and fruit consumption. There was no change in the consumption of milk, yoghurt, oily fish, tea, carbonated drinks and vegetables (Table 5).

\section{Differences in mean intakes of nutrients}

Comparison between mean nutrient intakes (from the diet only) showed small but statistically significant decreases in energy, fat, starch, protein and carbohydrate. There were small increases $(<8 \%)$ in carotene, vitamin $\mathrm{C}$ and vitamin
$\mathrm{D}$; and decreases in retinol, vitamin $\mathrm{B}_{12}$, thiamin, magnesium, phosphorus, manganese, iron, copper, zinc and selenium (Table 6). Retinol was unusual in that the decrease was particularly marked (18\%). The change in alcohol intake (16\% increase) should perhaps be treated with caution as this variable was positively skewed, with $22 \%$ of women at baseline and $27 \%$ of women at follow-up consuming no alcohol at all. The percentage of women who had changed their ranking by more than one quartile was found to be of the order of 15\%, ranging from 13\% of women for fat, magnesium and monounsaturated fatty acids to $21 \%$ of women for retinol and selenium. In terms of nutrient density, as a result of the decrease in energy

Table 5 Changes in weekly consumption of key food groups over 5 years $(n=898)$

\begin{tabular}{|c|c|c|c|c|c|c|}
\hline \multirow{2}{*}{$\begin{array}{l}\text { Food }(g) \text { unless otherwise } \\
\text { specified }\end{array}$} & \multirow{2}{*}{$\frac{\text { First visit (V1) }}{\text { Mean (SD) }}$} & \multirow{2}{*}{$\frac{\text { Second visit (V2) }}{\text { Mean (SD) }}$} & \multicolumn{2}{|c|}{ Difference between visits* } & \multirow[b]{2}{*}{ Ranking ( $\%$ moved > 1 quartile) } & \multirow[b]{2}{*}{$\mathrm{Kw}$} \\
\hline & & & $n$ for $t$-test & Mean V1-V2 (SD) & & \\
\hline Red meat & $361(248)$ & $295(202)$ & 829 & $-67(190) \dagger$ & 15.5 & 0.42 \\
\hline Processed meat & $116(126)$ & 97 (127) & 568 & $-24(86) \dagger$ & 13.5 & 0.44 \\
\hline Poultry & $169(161)$ & $261(165)$ & 774 & $+82(169) \dagger$ & 30.8 & 0.03 \\
\hline White fish & $150(130)$ & $170(152)$ & 775 & $+12(94) \dagger$ & 20.3 & 0.38 \\
\hline Oily fish & $76(92)$ & $81(88)$ & 555 & $+2(67)$ & 17.1 & 0.40 \\
\hline Milk total & 2665 (1359) & $2623(1256)$ & 832 & $-8.4(1468)$ & 2.4 & 0.52 \\
\hline Full-fat & $649(1411)$ & $405(1161)$ & 95 & $-57(1083)$ & & \\
\hline Semi-skimmed & 1562 (1637) & 1758 (1573) & 436 & $-124(827)$ & & \\
\hline Skimmed & 455 (1103) & $460(1083)$ & 103 & $+2.9(839)$ & & \\
\hline Cheese full-fat & $95(88)$ & $88(75)$ & 782 & $-6.7(62) \dagger$ & 14.8 & 0.24 \\
\hline Cheese low-fat & $53(73)$ & $51(50)$ & 597 & $-8.8(47)$ & 20.1 & 0.24 \\
\hline Yoghurt & $353(381)$ & 395 (419) & 609 & $+20(354)$ & 13.5 & 0.45 \\
\hline Cereals & $164(137)$ & $192(137)$ & 708 & +31 (137)† & 16.3 & 0.41 \\
\hline Bread total & $586(421)$ & $520(357)$ & 863 & -49 (350)† & 20.5 & 0.32 \\
\hline White bread & $153(263)$ & $163(243)$ & 403 & $+15(204)$ & & \\
\hline Brown bread & $90(176)$ & 72 (153) & 229 & $-12(156)$ & & \\
\hline Wholemeal bread & $235(332)$ & $196(259)$ & 457 & -37 (244)† & & \\
\hline Rice/pasta & $362(293)$ & $415(299)$ & 801 & $+42(230) \dagger$ & 15.7 & 0.41 \\
\hline Potatoes & $604(307)$ & 547 (237) & 889 & $-49(283) \dagger$ & 17.6 & 0.36 \\
\hline Vegetables & $1326(638)$ & $1339(602)$ & 897 & $+16(533)$ & 14.1 & 0.44 \\
\hline Fruit & 1391 (903) & 1579 (928) & 879 & $+200(859) \dagger$ & 14.5 & 0.42 \\
\hline Carbonated drinks & 737 (1167) & 677 (1027) & 517 & $-11(695)$ & 15.4 & 0.48 \\
\hline Tea (no. of cups) & $21(17)$ & $21(17)$ & 666 & $-0.5(9.6)$ & 5.7 & 0.66 \\
\hline Coffee (no. of cups) & 18 (17) & $16(16)$ & 533 & $-2.4(10.4)$ & 10.1 & 0.61 \\
\hline Biscuits & $243(217)$ & $203(171)$ & 850 & $-29(145)$ & 15.1 & 0.13 \\
\hline Cakes & $145(148)$ & $137(141)$ & 690 & $-9(104)$ & 15.7 & 0.41 \\
\hline Puddings & $94(106)$ & $83(95)$ & 538 & $-6(81)$ & 19.7 & 0.36 \\
\hline
\end{tabular}

SD - standard deviation; Kw - weighted kappa.

${ }^{*}$ Paired $t$-test after natural log-transformation. Anti-logged results are shown.

tSignificant difference at the $1 \%$ level. 
Table 6 Change in daily nutrient intakes over 5 years $(n=898)$

\begin{tabular}{|c|c|c|c|c|c|c|}
\hline & $\begin{array}{c}\text { First } \\
\text { visit (V1) }\end{array}$ & $\begin{array}{l}\text { Second } \\
\text { visit (V2) }\end{array}$ & $\begin{array}{c}\text { Difference } \\
\text { between visits* }\end{array}$ & & & $\begin{array}{l}\text { Difference between } \\
\text { visits as nutrient } \\
\text { density* } †\end{array}$ \\
\hline Nutrient & Mean (SD) & Mean (SD) & Mean V1-V2 (SD) & Ranking ( $\%$ moved $>1$ quartile) & $\mathrm{Kw}$ & Mean (SD) \\
\hline Energy (MJ) & $8.2(2.3)$ & $7.9(2.2)$ & $-0.3(1.8) \S$ & 14.0 & 0.43 & \\
\hline Alcohol (g) & $6.7(7.9)$ & $6.8(8.4)$ & $1.1(5.8) \S$ & 14.7 & 0.49 & $1.3(4.9) \S$ \\
\hline Protein (g) & $81.4(22.5)$ & $79.4(21.4)$ & $-2(20) \S$ & 16.0 & 0.40 & $1(13) \ddagger$ \\
\hline Fat $(\mathrm{g})$ & $74.3(28.7)$ & $69.3(26.8)$ & $-4(22) \S$ & 12.9 & 0.45 & $-2(11) \S$ \\
\hline $\operatorname{MUFA}(\mathrm{g})$ & $27.9(10.0)$ & $26.3(9.5)$ & $-2(8) \S$ & 13.1 & 0.46 & $-1(4) \S$ \\
\hline PUFA (g) & $11.6(4.6)$ & $11.4(4.4)$ & $0(3.8)$ & 16.1 & 0.40 & $0(4)$ \\
\hline SFA $(g)$ & $30.3(12.8)$ & $28.3(12.2)$ & $-2(10) \S$ & 14.4 & 0.44 & $-2(10) \S$ \\
\hline Carbohydrate (g) & $246(71)$ & $241(70)$ & $-4(61) \ddagger$ & 14.4 & 0.42 & $4(28) \S$ \\
\hline Starch $(g)$ & $124(44)$ & $117(40)$ & $-6(40) \ddagger$ & 18.4 & 0.36 & $-2(25) \ddagger$ \\
\hline Sugar (g) & $121(39)$ & $123(40)$ & $2.1(33)$ & 14.9 & 0.42 & $6(27) \S$ \\
\hline Fibre $(\mathrm{g})$ & $16.3(5.7)$ & $16.1(5.6)$ & $-0.2(4.7)$ & 14.3 & 0.43 & $-0.2(4.7) \ddagger$ \\
\hline Calcium (mg) & 1055 (332) & 1033 (316) & -18 (290) & 16.0 & 0.41 & 19 (234)‡ \\
\hline Copper (mg) & $1.3(0.4)$ & $1.2(0.4)$ & $-0.1(0.4) \S$ & 16.1 & 0.39 & $-0.0(0.2) \S$ \\
\hline Iron (mg) & $12.7(4.1)$ & $12.2(3.9)$ & $-0.4(3.8) \S$ & 18.2 & 0.37 & $0.0(2.9)$ \\
\hline lodine $(\mu \mathrm{g})$ & $189(62)$ & $194(69)$ & $4(58) \ddagger$ & 18.2 & 0.37 & $11(50) \S$ \\
\hline Potassium (mg) & 3357 (788) & $3329(790)$ & -27 (665) & 15.0 & 0.43 & 92 (559)§ \\
\hline Magnesium (mg) & $315(84)$ & 307 (82) & $-6(70) \S$ & 13.6 & 0.43 & $4(47) \S$ \\
\hline Manganese (mg) & 3.5 (1.3) & 3.3 (1.2) & $-0.1(1.1) \S$ & 15.7 & 0.42 & $0(0.9)$ \\
\hline Phosphorus (mg) & $1483(400)$ & 1455 (389) & $-25(345) \ddagger$ & 15.1 & 0.41 & 27 (221)§ \\
\hline Selenium $(\mu \mathrm{g})$ & $70(38)$ & $66(35)$ & $-2.4(0.2) \S$ & 21.0 & 0.30 & $-0.1(24)$ \\
\hline Zinc (mg) & $10.1(2.9)$ & $9.5(2.6)$ & $-0.5(0.2) \S$ & 15.7 & 0.42 & -0.2 (1.7)§† \\
\hline Carotene $(\mu \mathrm{g})$ & 2124 (1265) & 2227 (1310) & 97 (942)§ & 14.9 & 0.41 & 172 (987)§ \\
\hline Folate $(\mu \mathrm{g})$ & $292.3(87.0)$ & 294.4 (89.2) & $1.9(78)$ & 15.1 & 0.39 & $12.6(66.0) \S$ \\
\hline Niacin (mg) & $19.8(5.8)$ & $19.4(5.6)$ & $-0.4(5.4)$ & 18.8 & 0.36 & $0.4(4.3) \S$ \\
\hline Retinol $(\mu \mathrm{g})$ & $821(602)$ & $665(513)$ & $-113(408) \ddagger$ & 20.2 & 0.33 & $-95(384) \S$ \\
\hline Riboflavin (mg) & $2.0(0.6)^{\prime}$ & $2.0(0.6)$ & $0(0.5)$ & 15.9 & 0.40 & $0.1(0.5) \ddagger$ \\
\hline Thiamin (mg) & $1.5(0.4)$ & $1.4(0.4)$ & $0(0.5) \S$ & 16.1 & 0.39 & $0(0.3)$ \\
\hline Vitamin $\mathrm{B}_{6}(\mathrm{mg})$ & $2.0(0.6)$ & $2.0(0.6)$ & $0(0.5)$ & 16.1 & 0.38 & $0.1(0.4) \S$ \\
\hline Vitamin $\mathrm{C}(\mathrm{mg})$ & $118.6(63.8)$ & $121.5(59.7)$ & 4.2 (55)‡ & 18.3 & 0.36 & $8.3(58)$ \\
\hline Vitamin D $(\mu \mathrm{g})$ & $3.9(2.5)$ & $4.1(2.4)$ & $0.2(2.1) \ddagger$ & 18.6 & 0.36 & $0.3(2.0) \S$ \\
\hline Vitamin E (mg) & $6.5(2.2)$ & $6.6(2.2)$ & $0.1(2)$ & 16.6 & 0.40 & $0.3(1.5) \S$ \\
\hline Vitamin $B_{12}(\mu \mathrm{g})$ & $7.2(3.9)$ & $6.5(3.4)$ & $-0.5(3.2) \S$ & 19.9 & 0.33 & $-0.3(3.0) \S$ \\
\hline
\end{tabular}

SD - standard deviation; MUFA - monounsaturated fatty acids; PUFA - polyunsaturated fatty acids; SFA - saturated fatty acids.

* Paired $t$-test after natural log-transformation if required (not necessary for nutrient density for macronutrients except alcohol, PUFA and SFA; minerals except iodine, selenium and manganese; and niacin, riboflavin). Anti-logged results are shown.

† Nutrient density standardised to an 8.0-MJ diet (nutrient intake divided by energy intake multiplied by 8).

$\ddagger$ Significant difference at the $5 \%$ level.

$\S$ Significant difference at the $1 \%$ level.

intake, there were small increases for most vitamins with the exception of retinol and vitamin $\mathrm{B}_{12}$, which decreased (Table 6). There were increases in nutrient density for calcium, magnesium and potassium while zinc and selenium had decreased. Intakes of fat and starch had decreased but there were small increases in protein, carbohydrate and sugar.

\section{Difference in mean intakes between menopausal/ HRT use groups}

There was no difference between intakes of food groups at baseline and intakes of food groups at follow-up according to menopausal/HRT groups by one-way analysis of variance (ANOVA) (data not shown). There were small differences in the percentage change in nutrient intake (from diet only) of some nutrients (Table 7). Some of the differences were statistically significant but this was a result of the past HRT user group having a mean increase in energy intake compared with the other groups, for which there was a decrease in energy intake. There was no difference between baseline nutrient intake and follow-up nutrient intake including energy according to menopausal/HRT groups by one-way ANOVA (not shown).

\section{Discussion}

Our findings are consistent with the results of the NDNS (1986/87 and 2000/01 surveys) in terms of increases in fruit intake and poultry consumption. However, in our study red meat consumption had decreased whereas it increased in the NDNS. A decrease in red meat consumption was shown in the NFS over the same period. However, this latter survey is based on overall food expenditure in the home and does not give details for categories of sex and age. Since the methodology of dietary assessment is completely different, we would advise caution when comparing its results with those of our own study. We did 
Table 7 Percentage change in nutrient intake over 5 years according to menopausal status/use of hormone replacement therapy (HRT) at the second visit $(n=898)^{\star}$

\begin{tabular}{|c|c|c|c|c|c|c|}
\hline & $\begin{array}{l}\text { Premenopausal } \\
\qquad(n=51)\end{array}$ & $\begin{array}{l}\text { Perimenopausal } \\
\qquad(n=96)\end{array}$ & $\begin{array}{l}\text { Postmenopausal } \\
\quad(n=348)\end{array}$ & $\begin{array}{l}\text { Past HRT users } \\
\quad(n=112)\end{array}$ & $\begin{array}{l}\text { Present HRT users } \\
\quad(n=286)\end{array}$ & $\begin{array}{c}\text { All† } \\
(n=898)\end{array}$ \\
\hline Energy (MJ) & -6.0 & -4.8 & -2.5 & 2.0 & -6.0 & $-3.6 \ddagger$ \\
\hline Protein (g) & -5.8 & -2.6 & -0.9 & 4.2 & -5.0 & -2.2 \\
\hline Fat $(\mathrm{g})$ & -7.4 & -8.2 & -5.2 & -0.4 & -9.0 & $-6.3 \ddagger$ \\
\hline Carbohydrate (g) & -4.7 & -2.8 & -0.7 & 3.3 & -4.2 & -1.8 \\
\hline Fibre (g) & -7.6 & -4.2 & 1.6 & 5.2 & -4.9 & $-1.4 \S$ \\
\hline Calcium (mg) & -1.4 & -4.5 & -2.1 & 3.2 & -3.0 & -1.8 \\
\hline Iron (mg) & -7.4 & -7.4 & -1.9 & 6.3 & -6.4 & $-3.5 \S$ \\
\hline Potassium (mg) & -2.3 & -2.0 & -0.1 & 2.7 & -2.3 & -0.8 \\
\hline Magnesium (mg) & -5.7 & -2.8 & -0.3 & 2.3 & -4.7 & $-2.1 \ddagger$ \\
\hline Phosphorus (mg) & -4.0 & -2.9 & -0.9 & 4.0 & -4.0 & $-1.8 \ddagger$ \\
\hline Selenium $(\mu \mathrm{g})$ & -9.5 & -0.7 & 0.1 & 5.3 & -11.2 & $-3.8 \ddagger$ \\
\hline Zinc $(\mathrm{mg})$ & -9.8 & -7.2 & -3.8 & 0.2 & -8.0 & $-5.5 \ddagger$ \\
\hline Carotene $(\mu \mathrm{g})$ & 4.3 & 6.1 & 6.8 & 13.8 & 0.0 & $5.2 \ddagger$ \\
\hline Folate $(\mu \mathrm{g})$ & -1.4 & -2.8 & 2.2 & 8.0 & -2.1 & $0.7 \S$ \\
\hline Retinol $(\mu \mathrm{g})$ & -12.4 & -21.3 & -18.1 & -6.8 & -20.2 & $-17.6 \ddagger$ \\
\hline Vitamin $B_{6}(\mathrm{mg})$ & 0.5 & -1.9 & 1.7 & 7.9 & -0.9 & $1.1 \S$ \\
\hline Vitamin C (mg) & 3.9 & 2.6 & 4.7 & 8.8 & 2.3 & 4.1 \\
\hline Vitamin D $(\mu \mathrm{g})$ & 9.0 & -2.5 & 2.2 & 27.6 & 3.4 & $5.5 \S$ \\
\hline Vitamin E (mg) & -1.7 & 0.8 & 3.8 & 9.1 & -3.8 & $1.4 \S$ \\
\hline Vitamin $B_{12}(\mu \mathrm{g})$ & -3.5 & -13.1 & -10.7 & 9.4 & -7.7 & $-7.5 \S$ \\
\hline
\end{tabular}

${ }^{*}$ At the baseline visit, 93\% women were premenopausal. Menopausal groups at the second visit are mutually exclusive.

† Comparison of groups by one-way analysis of variance.

$\ddagger$ Significant difference at the $5 \%$ level.

$\S$ Significant difference at the $1 \%$ level.

not observe the decrease in milk consumption that was seen in the NDNS. This is perhaps because our study cohort is more aware of the benefits of milk drinking in relation to bone health, which may be a limitation of our study. However, the NFS showed a decrease in whole milk but an increase in expenditure on other milk and cream. Also, although we observed an increase in fish consumption this was not related to oily fish. In contrast to the NDNS, we found a decrease in coffee drinking and no change in tea consumption. The NFS showed a small decrease in both tea and coffee consumption over this period. One notable change was that the mean energy intake in this population had decreased in spite of overall weight gain, which was reported previously ${ }^{16}$.

It had been assumed that, since the same food codes were used for analysis of the follow-up FFQs as had been used at baseline, the same database values would have been used for calculating the nutrient intakes. However, this was not the case and further investigation through discussions at MAFF revealed that, unbeknown to users of the database, the information provided on disk was not a true representation of the data in McCance and Widdowson's tables as had been assumed. To make the data the best available at the time, new information on the composition of certain foods had been added at various intervals and this had overwritten the data used at the first visit. Although the largest difference was found for vitamin D intake, it should be emphasised that the codes used were for McCance and Widdowson's fifth edition ${ }^{13}$ and did not include the newer values on vitamin $\mathrm{D}$ in meat, over which there is still some debate. The difference in vitamin
D between the original baseline and follow-up FFQs would have even been greater if the meat food codes in McCance and Widdowson's supplement on meats, poultry and game had been used ${ }^{17}$. After reanalysing the baseline data it was found that, as a result of the overall energy of the diet being reduced at the second visit intakes of most nutrients had decreased slightly with the exception of iodine (through increased fish intake), carotene, vitamin $\mathrm{C}$, folate (through increased fruit), vitamin $\mathrm{B}_{6}$ (increased cereal) and vitamin D. Although adjustments to the vitamin D content of meats were made after $1995-96^{17}$, this study used the original vitamin $\mathrm{D}$ values for comparison of baseline and follow-up diets. The new values assume that $25(\mathrm{OH})$ cholecalciferol has five times the biological activity of cholecalciferol, but there are different opinions as to the potency factor used for the vitamin D metabolites ${ }^{18,19}$. It has been suggested that meat could be the richest natural source of vitamin D in the diet of British adults ${ }^{20}$. If this is the case, then trends regarding meat intake will affect dietary vitamin D intakes. Data from the NFS shown in the COMA report shows an apparent increase in vitamin D intake for 1995 and 1996 as a result of introducing these new figures ${ }^{21}$.

Using nutrient density data gives a measure of dietary quality, since it standardises the data to fixed energy intake and may also help minimise the bias caused by underreporting $^{22}$. In terms of diet quality, most micronutrients had increased by small amounts over 5 years. The reduced intakes of retinol and vitamin $\mathrm{B}_{12}$ in terms of nutrient density are likely to reflect reduced consumption of red meat/offal. The NDNS of British adults carried out 
in $1986 / 87$ indicated that $61 \%$ of retinol was derived from meat and meat products and almost all of this was from liver and liver products ${ }^{23}$, but this had decreased to $28 \%$ in the recent survey. Likewise, over half the intake of vitamin $\mathrm{B}_{12}$ was obtained from meat and meat products in $1986 / 87^{24}$ but in the recent NDNS survey (2000/01) this appeared to be lower, with milk and milk products now being the major contributor to vitamin $\mathrm{B}_{12}$ intake $\mathrm{e}^{25}$. With both these nutrients it is probably the decrease in offal that is the explanation for the difference between the surveys. Cereals, meat and fish provide most of the selenium in the diet, with cereals providing about half ${ }^{26}$. However, in our study of Scottish women we found that intakes of cereals and non-oily fish had increased. The decrease in energy intake in our study appeared to be caused by a reduction, across the board, in macronutrient intake. On closer examination, in terms of nutrient density, there was a trend for fat and starch intakes being selectively reduced as a slight increase in protein and carbohydrate was observed. It is possible this reflects a shift in dietary patterns or a bias due to the low energy reporters ${ }^{27}$.

All women were included in this analysis since the exclusion of low energy reporters would bias the data towards higher mean intakes ${ }^{28}$. The degree of underreporting found in the recent NDNS of British adults was $25 \%{ }^{29}$. Depending on the EI/BMR cut-off, the percentage of low energy reporters at the second visit of our study could range from 26 to 38\%. It should be emphasised that the validity of predicted BMR for early postmenopausal women is not certain, and BMR may change as a result of body composition changes. Low energy reporters of 7-day weighed intakes (over 20\% in a study of 1898 subjects) were characterised as being overweight and having greater $\mathrm{BMI}^{30}$. They were also less likely to underreport if as a child they belonged to social class III (non-manual), were currently employed, or had more children living with them. Reporting bias in a dietary study of London-based civil servants was influenced by socio-economic status ${ }^{22}$. In our study we did not observe any difference in social deprivation category between low energy reporters and normal energy reporters. It is possible that not all foods are covered by the 98-food item FFQ and this will lead to apparent underreporting. Compared with normal energy reporters, more than twice the low energy reporters claimed to be on weight-reducing diets. These women would have deliberately reduced their intake, and their energy intake, although lower than the EI/BMR cut-off of 1.1 for underreporting, may be a true representation of their intake at the time of the dietary assessment.

Ranking of individuals is particularly appropriate when using FFQ data for studying the influence of diet on disease outcomes. Therefore it is important to know whether ranking of individuals changes over time. Currently, there is a lack of evidence for determining the stability of ranked dietary data. Although it is recognised that women near the division of categories may change category as a result of a small change in diet, use of weighted kappa (Kw) allows for a different emphasis depending on the number of categories moved ${ }^{15}$. We noted greater differences in ranking of individuals with regard to certain food groups, in comparison to nutrients. For poultry in particular there was very poor agreement between intake at the two visits, with Kw of only 0.03 . In terms of nutrient intake ranking, our analysis showed little movement for the majority of our women, and for only $15 \%$ of this population had the diet changed substantially.

Vitamin or mineral supplement use was reported by about a third of the women at the follow-up visit, increasing from 25\% at baseline. Although dietary supplements can add to the total nutrient intake of the diet, our work suggests that usage may be sporadic and their contribution to the diet less than that assumed by measurement on a single occasion. In some cases the total reference nutrient intake will be exceeded, and it is important to establish whether sporadic, short-term use of supplements has any detrimental effect on health outcomes, and whether (e.g. in the case of retinol) high intakes consumed even on an occasional basis pose a problem for the future.

There is some concern that individuals perceive their diet with an accumulated mental image influenced by social desirability, rather than by recollection of diet as a series of discrete memory episodes, and this may affect their FFQ responses ${ }^{31-33}$. However, it was concluded that although measurement of diet by FFQ is not perfect, it does suffice as a tool for use in epidemiological studies ${ }^{33-36}$ and is as good a measure of diet (or better than) as are other instruments used for assessing blood pressure, or other physiological measures ${ }^{35}$.

There are few long-term, truly longitudinal studies of diet in the UK. This investigation examined 5-year change in diet in 898 perimenopausal and early postmenopausal women. We previously reported no difference in weight change between the groups ${ }^{16}$.

Some changes in food patterns over 5 years were observed but changes in nutrient intakes were small. There were no differences between menopausal status/HRT groups in terms of food intake or nutrient intake, either at baseline or follow-up, suggesting that the changes are not influenced by oestrogen status.

\section{Acknowledgements}

This work was funded by the Medical Research Council/Department of Health Nutrition Programme Phase II. Any views expressed are the authors' own. We are very grateful to David A Grubb for running the computer program for the FFQ analysis and to all the women who kindly took part in this study. D.M.R. gratefully acknowledges infrastructure support from the Arthritis Research Campaign. 


\section{References}

1 Prevost AT, Whichelow MJ, Cox BD. Longitudinal dietary changes between 1984-5 and 1991-2 in British adults: association with socio-demographic, lifestyle and health factors. British Journal of Nutrition 1997; 78: 873-88.

2 Department for Environment, Food and Rural Affairs, ed. National Food Survey 2000: Annual Report on Food Expenditure, Consumption and Nutrient Intakes. London: The Stationery Office, 2001.

3 Marriott H, Buttriss J. Key points from the National Diet and Nutrition Survey of adults aged 19-46 years. Nutrition Bulletin 2003; 28: 355-63.

4 New SA, Bolton-Smith C, Grubb DA, Reid DM. Nutritional influences on bone mineral density: a cross-sectional study in premenopausal women. American Journal of Clinical Nutrition 1997; 65: 1831-9.

5 Garton MJ, Torgerson DJ, Donaldson C, Russell IT, Reid DM. Recruitment methods of screening programmes: trial of a new method within a regional osteoporosis study. British Medical Journal 1992; 305: 82-4.

6 Torgerson DJ, Garton MJ, Donaldson C, Russell IT, Reid DM. Recruitment methods for screening programmes: trial of an improved method within a regional osteoporosis study. British Medical Journal 1993; 307: 99.

7 Macdonald HM, New SA, Golden MH, Campbell MK, Reid DM. Nutritional associations with bone loss during the menopausal transition: evidence of a beneficial effect of calcium, alcohol, and fruit and vegetable nutrients and of a detrimental effect of fatty acids. American Journal of Clinical Nutrition 2004; 79: 155-65.

8 Bolton-Smith C, Woodward M, Tunstall-Pedoe $H$. The Scottish Heart Health Study. Dietary intake by food frequency questionnaire and odds ratios for coronary heart disease risk. I. The macronutrients. European Journal of Clinical Nutrition 1992; 46: 75-84.

9 Bolton-Smith C, Woodward M, Tunstall-Pedoe $H$. The Scottish Heart Health Study. Dietary intake by food frequency questionnaire and odds ratios for coronary heart disease risk. II. The antioxidant vitamins and fibre. European Journal of Clinical Nutrition 1992; 46: 85-93.

10 Yarnell JWG, Fehily AM, Milbank JE, Sweetnam PM, Walker CL. A short dietary questionnaire for use in an epidemiological study: comparison with weighed dietary records. Human Nutrition: Applied Nutrition 1983; 37A: 103-12.

11 New SA. An epidemiological investigation into the influence of nutritional factors on bone mineral density and bone metabolism. PhD thesis, University of Aberdeen, UK, 1995.

12 Bodner CH, Soutar A, New SA, Scaife AR, Byres M, Henderson FD et al. Validation of a food frequency questionnaire for use in a Scottish population: correlation of antioxidant vitamin intakes with biochemical measures. Journal of Human Nutrition and Dietetics 1998; 11: 373-80.

13 Holland B, Welch AA, Unwin ID, Buss DH, Paul AA, Southgate DAT. McCance \& Widdowson's The Composition of Foods, 5th ed. Ministry of Agriculture, Fisheries and Food and Royal Society of Chemistry. London: HMSO, 1991.

14 Tunstall-Pedoe H, Smith WCS, Crombie IK, Tavendale R. Coronary risk factor and lifestyle variation across Scotland: results from the Scottish Heart Health Study. Scottish Medical Journal 1989; 34: 556-60.

15 Landis JR, Koch GG. An application of hierarchical kappatype statistics in the assessment of majority agreement among multiple observers. Biometrics 1977; 33: 363-74.

16 Macdonald HM, New SA, Campbell MK, Reid DM. Longitudinal changes in weight in perimenopausal and early postmenopausal women: effects of dietary energy intake, energy expenditure, dietary calcium intake and hormone replacement therapy. International Journal of Obesity and Related Metabolic Disorders 2003; 27: 669-76.

17 Chan W, Brown J, Lee SJ, Buss DH. Meat, Poultry and Game. Fifth Supplement to McCance \& Widdowson's The Composition of Foods, 5th ed. Ministry of Agriculture, Fisheries and Food and Royal Society of Chemistry. London: HMSO, 1995.

18 Reeve L, Jorgensen NA, DeLuca HF. Vitamin D compounds in cows' milk. Journal of Nutrition 1982; 112: 667-72.

19 Hollis BW, Roos BA, Draper HH, Lambert PW. Vitamin D and its metabolites in human and bovine milk. Journal of Nutrition 1981; 111: 1240-8.

20 Gibson SA, Ashwell M. New vitamin D values for meat and their implication for vitamin D intake in adults. Proceedings of the Nutrition Society 1997; 56: 116A.

21 Department of Health. Nutrition and Bone Health: With Particular Reference to Calcium and Vitamin D. London: HMSO, 1998.

22 Stallone DD, Brunner EJ, Bingham SA, Marmot MG. Dietary assessment in Whitehall II: the influence of reporting bias on apparent socioeconomic variation in nutrient intakes. European Journal of Clinical Nutrition 1997; 51: 815-25.

23 Gregory J, Foster F, Tyler H, Wiseman M. The Dietary and Nutritional Survey of British Adults. London: HMSO, 1990.

24 Ministry of Agriculture, Fisheries and Food. The Dietary and Nutritional Survey of British Adults: Further Analysis. London: HMSO, 1994.

25 Henderson L, Irving K, Gregory J, Bates CJ, Prentice A, Perks J, et al. (2003) National Diet and Nutrition Survey: Adults aged 19 to 64 Years. Vol. 3: Vitamin and Minerals Intake and Urinary Analytes. London: The Stationery Office.

26 Department of Health. Dietary Reference Values for Food Energy and Nutrients for the United Kingdom. London: HMSO, 1991.

27 Heitmann BL, Lissner L. Dietary underreporting by obese individuals - is it specific or non-specific? British Medical Journal 1995; 311: 986-9.

28 Bolton-Smith C, Smith WCS, Woolward M, Tunstall-Pedoe H. Nutrient intakes of different social-class groups: results from the Scottish Heart Health Study (SHHS). British Journal of Nutrition 1991; 65: 321-35.

29 Henderson L, Gregory J, Irving K, Swan G. National Diet and Nutrition Survey: Adults aged 19 to 64 Years. Vol. 2: Energy, Protein, Carbohydrate, Fat and Alcobol Intake. London: The Stationery Office, 2003.

30 Price GM, Paul AA, Cole TJ, Wadsworth ME. Characteristics of the low-energy reporters in a longitudinal national dietary survey. British Journal of Nutrition 1997; 77: 833-51.

31 Drewnowski A. Diet image: a new perspective on the foodfrequency questionnaire. Nutrition Reviews 2001; 59: 370-2.

32 Willett WC. Accuracy of food-frequency questionnaires. American Journal of Clinical Nutrition 2000; 72: 1234-6.

33 Willett W. Invited commentary: a further look at dietary questionnaire validation. American Journal of Epidemiology 2001; 154: 1100-2; discussion 1105-6.

34 Byers T. Food frequency dietary assessment: how bad is good enough? American Journal of Epidemiology 2001; 154: 1087-8.

35 Block G. Invited commentary: another perspective on food frequency questionnaires. American Journal of Epidemiology 2001; 154: 1103-4; discussion 1105-6.

36 Subar AF, Thompson FE, Kipnis V. Subar et al. respond to a further look at dietary questionnaire validation and another perspective on food frequency questionnaires. American Journal of Epidemiology 2001; 154: 1105-6. 